\title{
A Two-dimensional Mathematical Model for Long-term Contaminated Groundwater Pollution Measurement around a Land Fill
}

\author{
Jirapud Limthanakul ${ }^{1}$, Nopparat Pochai ${ }^{2, *}$ \\ ${ }^{1}$ Department of Mathematics, Faculty of Science, King Mongkut's Institute of Technology Ladkrabang, Bangkok 10520, Thailand \\ ${ }^{2}$ Centre of Excellence in Mathematics, Commission on Higher Education(CHE), Si Ayutthaya Road, Bangkok 10400, Thailand
}

Received November 22, 2019; Revised December 19, 2019; Accepted December 25, 2019

Copyright (C) 2020 by authors, all rights reserved. Authors agree that this article remains permanently open access under the terms of the Creative Commons Attribution License 4.0 International License

\begin{abstract}
A source of contaminated groundwater is governed by the disposal of waste material on a land fill. There are many people in rural areas where the primary source of drinking water is well water. This well water may be contaminated with groundwater from landfills. In this research, a two-dimensional mathematical model for long-term contaminated groundwater pollution measurement around a land fill is proposed. The model is governed by a combination of two models. The first model is a transient two-dimensional groundwater flow model that provides the hydraulic head of the groundwater. The second model is a transient twodimensional advection-diffusion equation that provides the groundwater pollutant concentration. The proposed explicit finite difference techniques are used to approximate the hydraulic head and the groundwater pollutant concentration. The simulations can be used to indicate when each simulated zone becomes a hazardous zone or a protection zone.
\end{abstract}

Keywords Groundwater Pollution, Landfill, Contamination, Finite Difference Method, Two-dimensional

\section{Introduction}

The importance of the utilization of groundwater resources continues to grow due to the increasing requirement for water for irrigation, drinking, commercial, agricultural and industrial proposes. From this, we can see that water become an even more important part of human life. What is the effect of contaminated water on humans? Contaminated groundwater can enter the food chain and cause many life-threatening diseases and problems. The effect of drinking contaminated or dirty water causes waterborne disease. Contaminated water can cause many types of diarrheal diseases, including Cholera, and other serious illnesses, such as Guinea worm disease, Typhoid and Dysentery. The solution to this problem is to approximate when the water from the primary source of drinking will become a hazardous zone. Hence, sustainable management planning must be developed for groundwater systems. In general, the level of pollution in groundwater can be ascertained from field data sites. However, this is rather complicated, and the results obtained tentatively deviate in measurement from one point in each time/place.

In [3], the modified MacCormack scheme improved accuracy in water quality measurement in a nonuniform water flow in a stream. A mathematical model was used to simulate a water current and the elevation in a uniform reservoir in [6]. There was some research that concerned solving the dispersal of pollutants in a river in [8]. Groundwater models and their application were represented in [1,2]. Transient groundwater modeling using spreadsheet simulation can be solved by using the finite difference method, which was described in [1]. The results are combined with MODFLOW results, a well-known model code for groundwater modeling. The objective of [2] was to propose a simple and flexible difference method and consider the complex geometry by using grid sizes aquifer parameters, sinks, and source terms. In this research, we consider groundwater that has been contaminated by waste material on a landfill. The simulation of the contaminated groundwater pollution model required data concerned with the velocity of the current points and any time in the domain. The transient two-dimensional groundwater flow model provided the velocity field of the groundwater. We used the transient two-dimensional advection-diffusion equation to approximate the groundwater pollutant concentration. The finite difference $[9,10,11]$ and finite elements methods [12, 13, 14] are the most popular numerical solution techniques. Among of these, finite difference methods, including both explicit and implicit schemes, are mostly used for two-dimensional domain such as in latitude and longitude stream.

These two mathematical models were used to simulate contaminated groundwater pollution. The first was a transient 


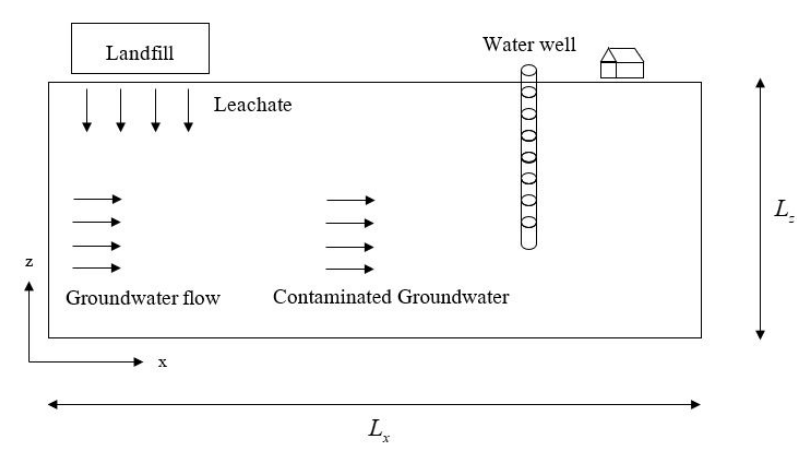

Figure 1. General structure of problem domain.

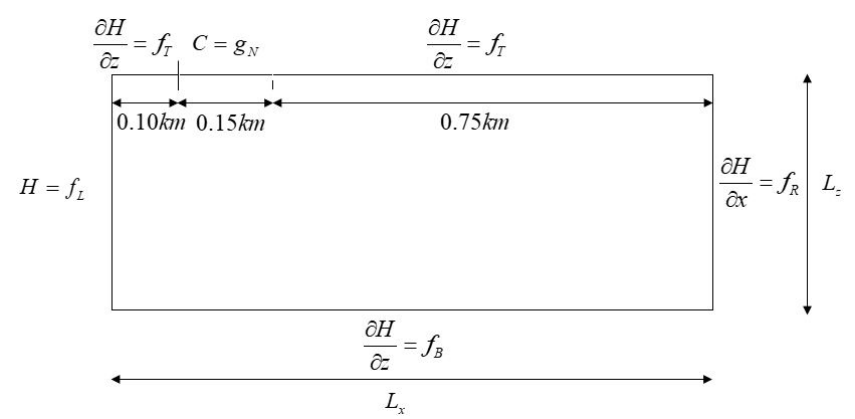

Figure 2. General structure of problem domain.

two-dimensional groundwater flow model that provided the hydraulic head of the groundwater. The second was a transient two-dimensional advection diffusion equation that gave the groundwater pollutant concentration. Both of the models were formulated in two-dimensional equations. The explicit method was used in both models. For each time, the calculated flow velocity fields of the first model were inputted into the second model as the field data.

\section{Governing equation}

\subsection{Transient groundwater flow model}

The governing equation of a latitudinally integrated Darcy's flow in a two-dimensional advection-diffusion equation [1],

$S \frac{\partial H(x, z, t)}{\partial t}=\frac{\partial}{\partial x}\left(K_{x} \frac{\partial H(x, z, t)}{\partial x}\right)+\frac{\partial}{\partial z}\left(K_{z} \frac{\partial H(x, z, t)}{\partial z}\right)$

where $H(x, z, t)$ is the hydraulic head(metre), $S$ matrix of specific storage(1/metre), $L_{x}$ is the considered area length, $L_{z}$ is the depth of considered groundwater area, $T$ is the stationary time of simulation as shown in Figure 1. The hydraulic conductivity(metre/day) component in the $x, z$ directions are denoted by $K_{x}, K_{z}$, respectively. Assuming that the soil topography in the considered area is homogeneous, these mean that the hydraulic conductivity are constant.

$$
S \frac{\partial H(x, z, t)}{\partial t}=K_{x} \frac{\partial^{2} H(x, z, t)}{\partial x}+K_{z} \frac{\partial^{2} H(x, z, t)}{\partial z} .
$$

for all $(x, z, t) \in \Omega$ such that $\Omega=\left[0, L_{x}\right] \times\left[0, L_{z}\right] \times[0, T]$.

\subsection{Initial and boundary condition of transient groundwater flow model}

\subsubsection{The initial condition of transient groundwater flow model}

The initial condition is defined by an interpolation function of measured raw data as be low

$$
H(x, z, 0)=h(x, z)
$$

where $h(x, z)$ is a given potential hydraulic head function.

\subsubsection{The boundary conditions}

The top, right and bottom boundary conditions are assumed by the averaged rate of change of hydraulic head around the top, right and bottom boundaries. The left boundary condition is assumed by the interpolation function of measured raw data in the considered landfill as shown in Figure 1. The boundary condition, are also assumed by

$$
\begin{gathered}
h(x, z, t)=h_{L}(z), \text { for all } z \in\left[0, I_{z}\right] \text { and } x=0, \\
\frac{\partial h(x, z, t)}{\partial z}=h_{T}(x), \text { for all } x \in\left[0, I_{x}\right] \text { and } z=M_{z}, \\
\frac{\partial h(x, z, t)}{\partial x}=h_{R}(z), \text { for all } z \in\left[0, I_{z}\right] \text { and } x=M_{x}, \\
\frac{\partial h(x, z, t)}{\partial z}=h_{B}(x), \text { for all } x \in\left[0, I_{x}\right] \text { and } z=0,
\end{gathered}
$$

where $h_{L}(z), h_{T}(x), h_{R}(z)$ and $h_{B}(x)$ are the boundary source of hydraulic head on the left boundary domain. The rate of change hydraulic head with respect to domain boundaries around the top, the bottom and the right bottom around the considered area as shown in Figure 3, respectively.

\subsection{Groundwater flow velocity model}

We can obtain that the groundwater flow velocity in $x$ direction is a decreasing rate of change of the hydraulic head $x$-direction,

$$
u=-\frac{\partial H}{\partial x}
$$

Similarly, the groundwater flow velocity in $z$-direction is a decreasing rate of change of the hydraulic head in $z$-direction,

$$
w=-\frac{\partial H}{\partial z} .
$$

\subsection{A horizontal averaged contaminated groundwater dispersion model}

A horizontal averaged two-dimensional advection-diffusion equation $(\mathrm{ADE})$ is expressed as follow

$$
\begin{aligned}
& \frac{\partial c(x, z, t)}{\partial t}+u \frac{\partial c(x, z, t)}{\partial x}+w \frac{\partial c(x, z, t)}{\partial z} \\
& =D_{x} \frac{\partial^{2} c(x, z, t)}{\partial x^{2}}+D_{z} \frac{\partial^{2} c(x, z, t)}{\partial z^{2}}+Q
\end{aligned}
$$


for all $(x, z, t) \in \Omega$ such that $\Omega=\left[0, L_{x}\right] \times$ $\left[0, L_{z}\right] \times[0, T]$, where $c(x, z, t)$ is the groundwater pollutant concentration $\left(\mathrm{kg} / \mathrm{m}^{3}\right), D_{x}, D_{z}$ are the diffusion coefficient in $x$ - and $z$-directions and $u(x, z, t), w(x, z, t)$ are the groundwater flow velocity in the $x$ - and $z$-directions.

\subsection{Initial and boundary conditions of the con- taminated groundwater dispersion model}

\subsubsection{Initial condition of the contaminated groundwater dispersion model}

The initial condition is defined by an interpolation function of the potential groundwater pollutant concentration,

$$
c(x, z, 0)=c_{0}(x, z) .
$$

for all $(x, z) \in\left[0, L_{x}\right] \times\left[0, L_{z}\right]$.

\subsubsection{The boundary conditions}

The left boundary condition is assumed by the interpolation function of measured raw data at the considered landfill. The top, right and bottom boundary conditions are assumed by the averaged rates of change of pollutant concentration around the top, right and bottom boundaries. The boundary conditions are also assumed by

$$
\begin{aligned}
& c\left(L_{z}, x, t\right)=g_{N}(x), \text { for all } x \in\left[k_{1} L_{x}, k_{2} L_{x}\right] \\
& \frac{\partial c(z, 0, t)}{d x}=g_{L}(z), \quad \text { for all } z \in\left[0, L_{z}\right] \text { and } t \in[0, T]
\end{aligned}
$$

$$
\begin{array}{ll}
\frac{\partial c\left(L_{z}, x, t\right)}{d z}=g_{T}(x), & \text { for all } x \in\left[0, k_{1} L_{x}\right) \cup\left(k_{2} L_{x}, L_{x}\right] \\
& \text { and } t \in[0, T], \\
\frac{\partial c\left(z, L_{x}, t\right)}{d x}=g_{R}(z), & \text { for all } z \in\left[0, L_{x}\right] \text { and } t \in[0, T],
\end{array}
$$

$$
\frac{\partial c(x, 0, t)}{d z}=g_{B}(x), \quad \text { for all } x \in\left[0, L_{x}\right] \text { and } t \in[0, T] \text {, }
$$

where $k_{1} L_{x}, k_{2} L_{x}$ are referred to the range area of the groundwater pollutant area source, and $g_{L}(z), g_{T}(x), g_{R}(z)$ and $g_{B}(x)$ are the rate of change pollutant concentration with respect distance around the top, the bottom and the right boundaries along the considered area, respectively.

\section{Numerical techniques}

In this paper, we will propose finite difference methods to the transient groundwater model by using the forward time central space method. We now discretize the domain by dividing the interval $\left[0, L_{x}\right]$ and $\left[0, L_{z}\right]$ into $M_{x}$ and $M_{z}$ subintervals such that $M_{x} \Delta x=L_{x}, M_{z} \Delta z=L_{z}$ and the time interval $[0, T]$ into $N$ subintervals such that $N \Delta t=T$. The grid points $\left(x_{i}, z_{j}, t_{n}\right)$ are defined by $x_{i}=i \Delta x$ for all $i=1,2, \ldots, M_{x}$,

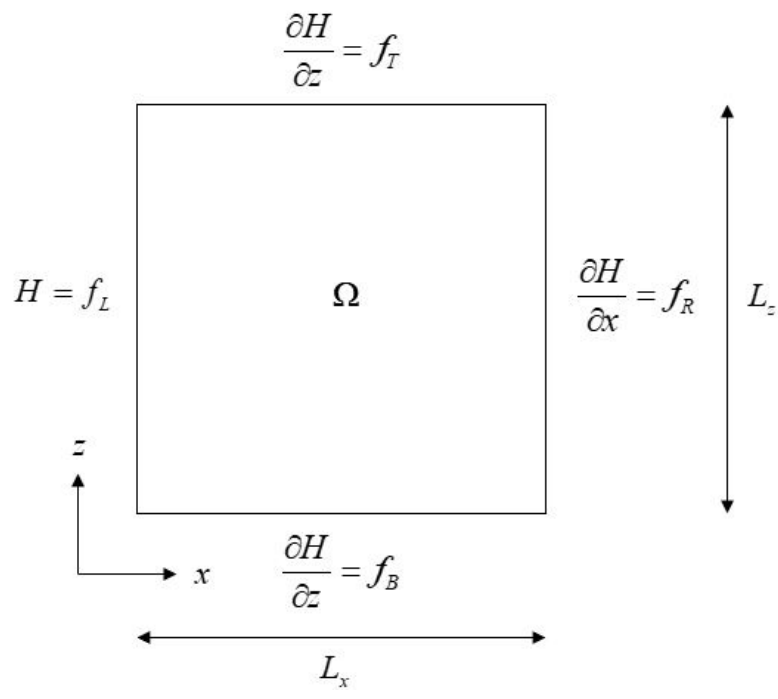

Figure 3. Boundary conditions of a transient groundwater flow model.

$z_{j}=j \Delta z$ for all $j=1,2, \ldots, M_{z}$ and $t_{n}=n \Delta t$ for all $n=1,2, \ldots, T$. We can then approximate $H\left(x_{i}, z_{j}, t_{n}\right)$ by $H_{i, j}^{n}$, value of the difference approximation of $H(x, z, t)$ at point $x=i \Delta x, z=j \Delta z$ and $t=n \Delta t$, where $0 \leq i \leq$ $M_{x}, 0 \leq j \leq M_{z}$ and $0 \leq n \leq N$ which $M_{x}, M_{z}$ and $N$ are positive integers.

\subsection{Explicit finite difference method for two- dimensional groundwater flow model}

Taking the central difference in space and forward difference in time into scheme each terms of Eq. (2.2), we have

$$
\begin{aligned}
H(x, z, t) & \simeq H_{i, j}^{n}, \\
\left.\frac{\partial H}{\partial t}\right|_{\left(x_{i}, z_{j}, t_{n}\right)} & \simeq \frac{H_{i, j}^{n+1}-H_{i, j}^{n}}{\Delta t}, \\
\left.\frac{\partial^{2} H}{\partial x^{2}}\right|_{\left(x_{i}, z_{j}, t_{n}\right)} & \simeq \frac{H_{i, j-1}^{n}-2 H_{i, j}^{n}+H_{i, j+1}^{n}}{(\Delta x)^{2}}, \\
\left.\frac{\partial^{2} H}{\partial z^{2}}\right|_{\left(x_{i}, z_{j}, t_{n}\right)} & \simeq \frac{H_{i-1, j}^{n}-2 H_{i, j}^{n}+H_{i+1, j}^{n}}{(\Delta z)^{2}} .
\end{aligned}
$$

Substituting Eqs.(3.1)-(3.4) into Eq.(2.2), we get the finite equation,

$$
\begin{aligned}
S\left(\frac{H_{i, j}^{n+1}-H_{i, j}^{n}}{\Delta t}\right) & =K_{x}\left(\frac{H_{i, j-1}^{n}-2 H_{i, j}^{n}+H_{i, j+1}^{n}}{(\Delta x)^{2}}\right) \\
& +K_{z}\left(\frac{H_{i-1, j}^{n}-2 H_{i, j}^{n}+H_{i+1, j}^{n}}{(\Delta z)^{2}}\right)
\end{aligned}
$$

for all $i=1,2,3, \ldots, M_{x}, j=1,2,3, \ldots, M_{z}$ and $n=$ $1,2,3, \ldots, N-1$. Then the explicit finite difference equation becomes

$$
\begin{aligned}
H_{i, j}^{n+1} & =\alpha H_{i, j-1}^{n}+\alpha H_{i, j+1}^{n}+(1-2 \alpha-2 \beta) H_{i, j}^{n} \\
& +\beta H_{i-1, j}^{n}+\beta H_{i+1, j}^{n},
\end{aligned}
$$


where $\alpha=\frac{K_{x}(\Delta t)}{S(\Delta x)^{2}}$ and $\beta=\frac{K_{z}(\Delta t)}{S(\Delta z)^{2}}$, for all $i=$ $1,2, \ldots, M_{x}-1$ and $j=1,2, \ldots, M_{z}-1$. According to the right boundary condition Eqs.(2.5) - (2.7), substituting the approximated unknown value to each boundaries,

For $j=M_{x}$ and $0<i<M_{z}-1$ at $t>0$, letting that

$$
H_{i, M_{x}+1}^{n}=H_{i, M_{x}}^{n}+f_{R}(z) \Delta x .
$$

It follow that

$$
\begin{aligned}
H_{i, M_{x}}^{n+1} & =\alpha H_{i, M_{x}-1}^{n}+(1-\alpha-2 \beta) H_{i, M_{x}}^{n}+\beta H_{i-1, M_{x}}^{n} \\
& +\beta H_{i+1, M_{x}}^{n}+\alpha f_{R}(z) \Delta x
\end{aligned}
$$

For $i=0$ and $0<j<M_{x}-1$ at $t>0$, letting that

$$
H_{-1, j}^{n}=H_{0, j}^{n}-f_{B}(x) \Delta z
$$

It follow that

$$
\begin{aligned}
H_{0, j}^{n+1} & =\alpha H_{0, j-1}^{n}+\alpha H_{0, j+1}^{n}+(1-2 \alpha-\beta) H_{0, j}^{n} \\
& +\beta H_{1, j}^{n}-\beta f_{B}(x) \Delta z .
\end{aligned}
$$

For $i=M_{z}$ and $0<j<M_{x}-1$ at $t>0$, letting that

$$
H_{M_{z}, j}^{n+1}=H_{M_{z}, j}^{n}+f_{T}(x) \Delta z .
$$

It follow that

$$
\begin{aligned}
H_{M_{z}, j}^{n+1} & =\alpha H_{M_{z}, j-1}^{n}+\alpha H_{M_{z}, j+1}^{n}+(1-2 \alpha-\beta) H_{M_{z}, j}^{n} \\
& +\beta H_{M_{z}-1, j}^{n}+\beta f_{T}(x) \Delta z .
\end{aligned}
$$

\subsection{Finite difference method for groundwater flow velocity model}

Taking the forward difference in space into Eq.(2.8) and Eq.(2.9), we have

$$
\begin{aligned}
v(x, z, t) & \simeq v_{i, j}^{n}, \\
w(x, z, t) & \simeq w_{i, j}^{n}, \\
\left.\frac{\partial H}{\partial x}\right|_{\left(x_{i}, z_{j}, t_{n}\right)} & \simeq \frac{H_{i, j+1}^{n}-H_{i, j}^{n}}{\Delta x}, \\
\left.\frac{\partial H}{\partial z}\right|_{\left(x_{i}, z_{j}, t_{n}\right)} & \simeq \frac{H_{i+1, j}^{n}-H_{i, j}^{n}}{\Delta z} .
\end{aligned}
$$

Substituting Eqs.(3.15) - (3.16) into (2.8) and (2.9), we get the finite equation,

$$
v_{i, j}^{n}=-\frac{1}{\Delta x}\left(H_{i, j+1}^{n}-H_{i, j}^{n}\right)
$$

and

$$
w_{i, j}^{n}=-\frac{1}{\Delta z}\left(H_{i+1, j}^{n}-H_{i, j}^{n}\right) .
$$

\subsection{Explicit finite difference method for two- dimensional groundwater pollution disper- sion model}

In this section, the considered domain is defined in a similar grid spacing as the previous. We will employ forward time central space difference scheme (FTCS) to Eqs.(2.10)

$$
\begin{aligned}
c(x, z, t) & \simeq C_{i, j}^{n}, \\
\left.\frac{\partial c}{\partial t}\right|_{\left(x_{i}, z_{j}, t_{n}\right)} & \simeq \frac{C_{i, j}^{n+1}-C_{i, j}^{n}}{\Delta t}, \\
\left.\frac{\partial c}{\partial x}\right|_{\left(x_{i}, z_{j}, t_{n}\right)} & \simeq \frac{C_{i, j-1}^{n}-C_{i, j+1}^{n}}{2 \Delta x}, \\
\left.\frac{\partial c}{\partial z}\right|_{\left(x_{i}, z_{j}, t_{n}\right)} & \simeq \frac{C_{i-1, j}^{n}-C_{i+1, j}^{n}}{2 \Delta z}, \\
\left.\frac{\partial^{2} c}{\partial x^{2}}\right|_{\left(x_{i}, z_{j}, t_{n}\right)} & \simeq \frac{C_{i, j-1}^{n}-2 C_{i, j}^{n}+C_{i, j+1}^{n}}{(\Delta x)^{2}}, \\
\left.\frac{\partial^{2} c}{\partial z^{2}}\right|_{\left(x_{i}, z_{j}, t_{n}\right)} & \simeq \frac{C_{i-1, j}^{n}-2 C_{i, j}^{n}+C_{i+1, j}^{n}}{(\Delta z)^{2}} .
\end{aligned}
$$

Substituting Eqs.(3.19) - (3.24) into (2.10), we get the finite equation,

$$
\begin{aligned}
& \frac{C_{i, j}^{n+1}-C_{i, j}^{n}}{\Delta t}+u_{i, j}^{n}\left(\frac{C_{i+1, j}^{n}-C_{i-1, j}^{n}}{2 \Delta x}\right)+w_{i, j}^{n}\left(\frac{C_{i, j+1}^{n}-C_{i, j-1}^{n}}{2 \Delta z}\right) \\
& =D_{x}\left(\frac{C_{i, j-1}^{n}-2 C_{i, j}^{n}+C_{i, j+1}^{n}}{(\Delta x)^{2}}\right)+D_{z}\left(\frac{C_{i-1, j}^{n}-2 C_{i, j}^{n}+C_{i+1, j}^{n}}{(\Delta z)^{2}}\right)
\end{aligned}
$$

$+Q$

for all $i=1,2,3, \ldots, M_{x}, j=1,2,3, \ldots, M_{z}$ and $n=$ $1,2,3, \ldots, N-1$. Then the explicit finite difference equation becomes

$$
\begin{aligned}
C_{i, j}^{n+1} & =\left(\tau_{1}+\tau_{2}\right) C_{i-1, j}^{n}+\left(\lambda_{1}+\lambda_{2}\right) C_{i, j-1}^{n}+\left(1-2 \lambda_{1}-2 \tau_{1}\right) C_{i, j}^{n} \\
& +\left(\tau_{1}-\tau_{2}\right) C_{i+1, j}^{n}+\left(\lambda_{1}-\lambda_{2}\right) C_{i, j+1}^{n}+Q \Delta t
\end{aligned}
$$

where $\lambda_{1}=\frac{D_{x} \Delta t}{(\Delta x)^{2}}, \lambda_{2}=\frac{u_{i, j}^{n} \Delta t}{2 \Delta x}, \tau_{1}=\frac{D_{z} \Delta t}{(\Delta z)^{2}}$. and $\tau_{2}=$ $\frac{w_{i, j}^{n} \Delta t}{2 \Delta z}$

According to the boundary condition Eqs.(2.13)-(2.16), substituting the approximate unknown value of the each boundary,

$$
\begin{aligned}
& \text { For } j=0 \text { and } 0<i<M_{z}-1 \text { at } t>0 \text {, letting that } \\
& \qquad C_{i,-1}^{n}=C_{i, 0}^{n}-g_{W}(z) \Delta x \\
& C_{i, 0}^{n+1}=\left(\tau_{1}+\tau_{2}\right) C_{i-1,0}^{n}+\left(1-\lambda_{1}-2 \tau_{1}-\tau_{2}\right) C_{i, 0}^{n} \\
& +\left(\tau_{1}-\tau_{2}\right) C_{i+1,0}^{n}+\left(\lambda_{1}-\lambda_{2}\right) C_{i, 1}^{n}+Q \Delta t \\
& -\left(\lambda_{1}-\lambda_{2}\right) g_{L}(z) \Delta x
\end{aligned}
$$

For $j=M_{x}$ and $0<i<M_{z}-1$ at $t>0$, letting that

$$
C_{i, M_{x}+1}^{n}=C_{i, M_{x}}^{n}+g_{R}(z) \Delta x .
$$


It follow that

$$
\begin{aligned}
& C_{i, M_{x}}^{n+1}=\left(\tau_{1}+\tau_{2}\right) C_{i-1, M_{x}}^{n}+\left(1-\lambda_{1}-2 \tau_{1}-\tau_{2}\right) C_{i, M_{x}}^{n} \\
& +\left(\tau_{1}-\tau_{2}\right) C_{i+1, M_{x}}^{n}+\left(\lambda_{1}+\lambda_{2}\right) C_{i, M_{x}-1}^{n}+Q \Delta t \\
& +\left(\lambda_{1}-\lambda_{2}\right) g_{R}(z) \Delta x
\end{aligned}
$$

For $i=0$ and $0<i<M_{x}-1$ at $t>0$, letting that

$$
C_{-1, j}^{n}=C_{0, j}^{n}-g_{B}(x) \Delta z .
$$

It follow that

$$
\begin{aligned}
& C_{0, j}^{n+1}=\left(\lambda_{1}+\lambda_{2}\right) C_{0, j-1}^{n}+\left(1-2 \lambda_{1}-\tau_{1}+\tau_{2}\right) C_{0, j}^{n} \\
& +\left(\tau_{1}-\tau_{2}\right) C_{1, j}^{n}+\left(\lambda_{1}-\lambda_{2}\right) C_{0, j+1}^{n}+Q \Delta t \\
& -\left(\tau_{1}+\tau_{2}\right) g_{B}(x) \Delta z
\end{aligned}
$$

For $i=M_{z}$ and $0<j<M_{x}-1$ at $t>0$, letting that

$$
C_{M_{z}+1, j}^{n}=C_{M_{z}, j}^{n}+g_{T}(x) \Delta z .
$$

It follow that

$$
\begin{aligned}
& C_{M_{z}, j}^{n+1}=\left(\tau_{1}+\tau_{2}\right) C_{M_{z}-1, j}^{n}+\left(1-2 \lambda_{1}-\tau_{1}-\lambda_{2}\right) C_{M_{z}, j}^{n} \\
& +\left(\lambda_{1}+\lambda_{2}\right) C_{M_{z}, j-1}^{n}+\left(\lambda_{1}-\lambda_{2}\right) C_{M_{z}, j+1}^{n}+Q \Delta t \\
& +\left(\tau_{1}-\tau_{2}\right) g_{T}(x) \Delta z .
\end{aligned}
$$

\section{Numerical simulations}

Suppose that the measurement of groundwater pollutant concentration $C$ in a groundwater flow is considered in an underground area. The considered underground area has dimensions of $1.0 \mathrm{~km}$ of length and $0.5 \mathrm{~km}$ in depth, $L_{x}=1.0 \mathrm{~km}$ and $L_{z}=0.5 \mathrm{~km}$, respectively. The simulations need to propose the measurement of the latitudinally averaged groundwater pollutant concentration in the considered area.

There is the landfill which is discharging leachate down to the considered under ground area. The landfill is aligned with longitudinal distance $0.15 \mathrm{~km}$, as shown in Figure 2. The landfill discharges the groundwater pollutant to the underground by $C(x, 0, t)=g_{N}(x)\left(\mathrm{kg} / \mathrm{m}^{3}\right)$ for all $0.1 \leq x \leq 0.25$.

Assume that the specific storage is $1 \mathrm{~m}^{-1}$ and the hydraulic conductivity in $x$ - and $z$-direction are 15 ( $\mathrm{m} /$ day). There is no rate of change of hydraulic head on the left, the right, the bottom of the considered domain boundaries. There is no rate of change of hydraulic head on the top boundary. We also assume that the leachate which is flowing down to the underground has a pollutant concentration of $1.0\left(\mathrm{~kg} / \mathrm{m}^{3}\right)$. There is no rate of change of pollutant concentration on the left, the right, the bottom domain boundaries. The related physical parameters are summarized in Table 1.

\subsection{Simulation 4.1. Low leachate pollutant re- lease rate with a low hydraulic head level.}

If the proposed explicit finite difference techniques for the two-dimensional groundwater flow model Eqs.(3.6), (3.8), (3.10) and (3.12) are employed, we get approximated hydraulic head, as shown in Table 2 and Figures 4-5. If the proposed explicit finite difference technique for the groundwater flow velocity model Eqs.(3.15)-(3.16) are employed, we get the approximated groundwater flow velocity in the $x$ - and $z$-direction in Table 3-4 and Figure 6. The approximated groundwater flow velocities are then plugged into the two-dimensional groundwater pollutant dispersion model. If the proposed explicit finite difference technique for the two-dimensional groundwater pollutant dispersion model Eqs.(3.25), (3.27), (3.29), (3.31) and (3.33) are employed, we get the approximated groundwater pollutant concentration as shown in Table 5 and Figures 7-8.

\subsection{Simulation 4.2. Low leachate pollutant re- leasing rate with a high hydraulic head level.}

If the proposed explicit finite difference techniques for the two-dimensional groundwater flow model Eqs.(3.6), (3.8), (3.10) and (3.12) are employed, we get an approximated hydraulic head as shown in Table 6 and Figures 9-10. If the proposed explicit finite difference technique for the groundwater flow velocity model Eqs.(3.15)-(3.16) are employed, we get the approximated groundwater flow velocity in the $x$ - and $z$-direction in Table 7-8 and Figure 11 . The approximated groundwater flow velocities are then plugged into the two-dimensional groundwater pollutant dispersion model. If the proposed explicit finite difference technique for the two-dimensional groundwater pollutant dispersion model Eqs.(3.25), (3.27), (3.29), (3.31) and (3.33) are employed, we get the approximated groundwater pollutant concentration as shown in Table 9 and Figures 12-13.

\subsection{Simulation 4.3 Medium leachate pollutant releasing rate with a high hydraulic head level.}

If the proposed explicit finite difference techniques for the two-dimensional groundwater flow model Eqs.(3.6), (3.8), (3.10) and (3.12) are employed, we get an approximated hydraulic head as shown in Table 10 and Figures 14-15. If the proposed explicit finite difference technique for the groundwater flow velocity model Eqs.(3.15)-(3.16) are employed, we get the approximated groundwater flow velocity in the $x$ - and $z$-direction in Table 11-12 and Figure 16. The approximated groundwater flow velocities are then plugged into the two-dimensional groundwater pollutant dispersion model. If the proposed explicit finite difference technique for the two-dimensional groundwater pollutant dispersion model Eqs.(3.25), (3.27), (3.29), (3.31) and (3.33) are employed, we get the approximated groundwater pollutant concentration as shown in Table 13 and Figures 17-18.

\subsection{Simulation 4.4. High leachate pollutant releasing rate with a high hydraulic head level.}

If the proposed explicit finite difference techniques for the two-dimensional groundwater flow model Eqs.(3.6), (3.8), 
(3.10) and (3.12) are employed, we get an approximated hydraulic head as shown in Table 14 and Figures 19-20. If the proposed explicit finite difference technique for the groundwater flow velocity model Eqs.(3.15)-(3.16) are employed, we get the approximated groundwater flow velocity in the $x$ - and $z$-direction in Table 15-16 and Figure 21. The approximated groundwater flow velocities are then plugged into the two-dimensional groundwater pollutant dispersion model. If the proposed explicit finite difference technique for the two-dimensional groundwater pollutant dispersion model Eqs.(3.25), (3.27), (3.29), (3.31) and (3.33) are employed, we get the approximated groundwater pollutant concentration as shown in Table 17 and Figures 22-23.

\subsection{Simulation 4.5. Practical leachate pollutant releasing rate with a high hydraulic head level.}

If the proposed explicit finite difference techniques for the two-dimensional groundwater flow model Eqs.(3.6), (3.8), (3.10) and (3.12) are employed, we get an approximated hydraulic head as shown in Table 18 and Figures 24-25. If the proposed explicit finite difference technique for the groundwater flow velocity model Eqs.(3.15)-(3.16) are employed, we get the approximated groundwater flow velocity in the $x$ - and $z$-direction in Table 19-20 and Figure 26. The approximated groundwater flow velocities are then plugged into the two-dimensional groundwater pollutant dispersion model. If the proposed explicit finite difference technique for the two-dimensional groundwater pollutant dispersion model Eqs.(3.25), (3.27), (3.29), (3.31) and (3.33) are employed, we get the approximated groundwater pollutant concentration as shown in Table 21 and Figures 27-28.

Table 1. The configuration in each simulations

\begin{tabular}{rlllllll}
\hline & $S$ & $K_{x}$ & $K_{z}$ & $f_{T}$ & $f_{B}$ & $f_{R}$ & $f_{L}$ \\
\hline Simulation 4.1 & 1 & 15 & 15 & 0 & 0 & 0 & 10 \\
Simulation 4.2 & 1 & 15 & 15 & 0 & 0 & 0 & 40 \\
Simulation 4.3 & 1 & 15 & 15 & 0 & 0 & 0 & 40 \\
Simulation 4.4 & 1 & 15 & 15 & 0 & 0 & 0 & 40 \\
Simulation 4.5 & 1 & 15 & 15 & 0 & 0 & 0 & $0.06 z+10$ \\
\hline$D_{x}$ & $D_{z}$ & $Q$ & $g_{N}$ & $g_{T}$ & $g_{B}$ & $g_{R}$ & $g_{L}$ \\
\hline 1.5 & 1.5 & 0 & 1 & 0 & 0 & 0 & 0 \\
1.5 & 1.5 & 0 & 1 & 0 & 0 & 0 & 0 \\
1.5 & 1.5 & 0 & 2 & 0 & 0 & 0 & 0 \\
1.5 & 1.5 & 0 & 4 & 0 & 0 & 0 & 0 \\
1.5 & 1.5 & 0 & 4 & 0 & 0 & 0 & 0 \\
\hline
\end{tabular}

Table 2. The approximated hydraulic head(m) of simulation 4.1 where $z=50$ $\mathrm{m}$.

\begin{tabular}{lllllll}
\hline \multicolumn{7}{c}{$H(x, z, t)$} \\
\hline$t$ & $x=0$ & $x=20$ & $x=40$ & $x=60$ & $x=80$ & $x=90$ \\
\hline 5 & 10.0000 & 9.3140 & 8.6331 & 7.9622 & 7.3061 & 6.9849 \\
10 & 10.0000 & 9.5147 & 9.0312 & 8.5512 & 8.0766 & 7.8418 \\
15 & 10.0000 & 9.6037 & 9.2083 & 8.8149 & 8.4244 & 8.2306 \\
20 & 10.0000 & 9.6568 & 9.3142 & 8.9729 & 8.6335 & 8.4647 \\
\hline
\end{tabular}

Table 3. The approximated groundwater flow velocity in $x$-direction(m/day) of simulation 4.1 where $z=50 \mathrm{~m}$.

\begin{tabular}{lllllll}
\hline \multicolumn{7}{c}{$u(x, z, t)$} \\
\hline$t$ & $x=0$ & $x=20$ & $x=40$ & $x=60$ & $x=80$ & $x=90$ \\
\hline 5 & 0.0343 & 0.0341 & 0.0337 & 0.0330 & 0.0321 & 0.0316 \\
10 & 0.0243 & 0.0242 & 0.0241 & 0.0238 & 0.0235 & 0.0233 \\
15 & 0.0198 & 0.0197 & 0.0196 & 0.0195 & 0.0193 & 0.0192 \\
20 & 0.0172 & 0.0171 & 0.0171 & 0.0170 & 0.0169 & 0.0167 \\
\hline
\end{tabular}

Table 4. The approximated groundwater flow velocity in $z$-direction(m/day) of simulation 4.1 where $z=50 \mathrm{~m}$.

\begin{tabular}{lllllll}
\hline \multicolumn{7}{c}{$w(x, z, t)$} \\
\hline$t$ & $x=0$ & $x=20$ & $x=40$ & $x=60$ & $x=80$ & $x=90$ \\
\hline 5 & 0 & 0 & 0 & 0 & 0 & 0 \\
10 & 0 & 0 & 0 & 0 & 0 & 0 \\
15 & 0 & 0 & 0 & 0 & 0 & 0 \\
20 & 0 & 0 & 0 & 0 & 0 & 0 \\
\hline
\end{tabular}

Table 5. The approximated groundwater pollutant concentration $\left(\mathrm{kg} / \mathrm{m}^{3}\right)$ of simulation 4.1 where $z=50 \mathrm{~m}$.

\begin{tabular}{lllllll}
\hline \multicolumn{7}{c}{$C(x, z, t)$} \\
\hline$t$ & $x=0$ & $x=20$ & $x=40$ & $x=60$ & $x=80$ & $x=90$ \\
\hline 5 & 0.0148 & 0.0198 & 0.0348 & 0.0654 & 0.1153 & 0.1467 \\
10 & 0.0683 & 0.0768 & 0.0997 & 0.1408 & 0.2006 & 0.2356 \\
15 & 0.1324 & 0.1419 & 0.1668 & 0.2094 & 0.2689 & 0.3029 \\
20 & 0.1945 & 0.2042 & 0.2289 & 0.2703 & 0.3269 & 0.3587 \\
\hline
\end{tabular}

Table 6. The approximated hydraulic head(m) of simulation 4.2 where $z=50$ $\mathrm{m}$.

\begin{tabular}{lllllll}
\hline \multicolumn{7}{c}{$H(x, z, t)$} \\
\hline$t$ & $x=0$ & $x=20$ & $x=40$ & $x=60$ & $x=80$ & $x=90$ \\
\hline 5 & 40.0000 & 37.2561 & 34.5325 & 31.8490 & 29.2244 & 27.9397 \\
10 & 40.0000 & 38.0587 & 36.1247 & 34.2049 & 32.3063 & 31.3670 \\
15 & 40.0000 & 38.4147 & 36.8333 & 35.2597 & 33.6977 & 32.9223 \\
20 & 40.0000 & 38.6272 & 37.2569 & 35.8918 & 34.5342 & 33.8590 \\
\hline
\end{tabular}

Table 7. The approximated groundwater flow velocity in $x$-direction(m/day) of simulation 4.2 where $z=50 \mathrm{~m}$.

\begin{tabular}{lllllll}
\hline \multicolumn{7}{c}{$u(x, z, t)$} \\
\hline$t$ & $x=0$ & $x=20$ & $x=40$ & $x=60$ & $x=80$ & $x=90$ \\
\hline 5 & 0.1371 & 0.1366 & 0.1348 & 0.1321 & 0.1285 & 0.1263 \\
10 & 0.0970 & 0.0968 & 0.0962 & 0.0952 & 0.0939 & 0.0931 \\
15 & 0.0792 & 0.0791 & 0.0788 & 0.0783 & 0.0775 & 0.0771 \\
20 & 0.0686 & 0.0686 & 0.0683 & 0.0680 & 0.0675 & 0.0672 \\
\hline
\end{tabular}

Table 8. The approximated groundwater flow velocity in $z$-direction(m/day) of simulation 4.2 where $z=50 \mathrm{~m}$.

\begin{tabular}{lllllll}
\hline \multicolumn{7}{c}{$w(x, z, t)$} \\
\hline$t$ & $x=0$ & $x=20$ & $x=40$ & $x=60$ & $x=80$ & $x=90$ \\
\hline 5 & 0 & 0 & 0 & 0 & 0 & 0 \\
10 & 0 & 0 & 0 & 0 & 0 & 0 \\
15 & 0 & 0 & 0 & 0 & 0 & 0 \\
20 & 0 & 0 & 0 & 0 & 0 & 0 \\
\hline
\end{tabular}

Table 9. The approximated groundwater pollutant concentration $\left(\mathrm{kg} / \mathrm{m}^{3}\right)$ of simulation 4.2 where $z=50 \mathrm{~m}$.

\begin{tabular}{lllllll}
\hline \multicolumn{7}{c}{$C(x, z, t)$} \\
\hline$t$ & $x=0$ & $x=20$ & $x=40$ & $x=60$ & $x=80$ & $x=90$ \\
\hline 5 & 0.0000 & 0.0000 & 0.0002 & 0.0013 & 0.0067 & 0.0735 \\
10 & 0.0006 & 0.0009 & 0.0023 & 0.0074 & 0.0226 & 0.0367 \\
15 & 0.0035 & 0.0042 & 0.0076 & 0.0174 & 0.0410 & 0.0601 \\
20 & 0.0097 & 0.0111 & 0.0164 & 0.0305 & 0.0605 & 0.0832 \\
\hline
\end{tabular}


Table 10. The approximated hydraulic head(m) of simulation 4.3 where $z=$ $50 \mathrm{~m}$.

\begin{tabular}{lllllll}
\hline \multicolumn{7}{c}{$H(x, z, t)$} \\
\hline$t$ & $x=0$ & $x=20$ & $x=40$ & $x=60$ & $x=80$ & $x=90$ \\
\hline 5 & 40.0000 & 37.2561 & 34.5325 & 31.8490 & 29.2244 & 27.9397 \\
10 & 40.0000 & 38.0587 & 36.1247 & 34.2049 & 32.3063 & 31.3670 \\
15 & 40.0000 & 38.4147 & 36.8333 & 35.2597 & 33.6977 & 32.9223 \\
20 & 40.0000 & 38.6272 & 37.2569 & 35.8918 & 34.5342 & 33.8590 \\
\hline
\end{tabular}

Table 11. The approximated groundwater flow velocity in $x$-direction(m/day) of simulation 4.3 where $z=50 \mathrm{~m}$.

\begin{tabular}{lllllll}
\hline \multicolumn{7}{c}{$u(x, z, t)$} \\
\hline$t$ & $x=0$ & $x=20$ & $x=40$ & $x=60$ & $x=80$ & $x=90$ \\
\hline 5 & 0.1371 & 0.1366 & 0.1348 & 0.1321 & 0.1285 & 0.1263 \\
10 & 0.0970 & 0.0968 & 0.0962 & 0.0952 & 0.0939 & 0.0931 \\
15 & 0.0792 & 0.0791 & 0.0788 & 0.0783 & 0.0775 & 0.0771 \\
20 & 0.0686 & 0.0686 & 0.0683 & 0.0680 & 0.0675 & 0.0672 \\
\hline
\end{tabular}

Table 12. The approximated groundwater flow velocity in $z$-direction(m/day) of simulation 4.3 where $z=50 \mathrm{~m}$.

\begin{tabular}{lllllll}
\hline \multicolumn{7}{c}{$w(x, z, t)$} \\
\hline$t$ & $x=0$ & $x=20$ & $x=40$ & $x=60$ & $x=80$ & $x=90$ \\
\hline 5 & 0 & 0 & 0 & 0 & 0 & 0 \\
10 & 0 & 0 & 0 & 0 & 0 & 0 \\
15 & 0 & 0 & 0 & 0 & 0 & 0 \\
20 & 0 & 0 & 0 & 0 & 0 & 0 \\
\hline
\end{tabular}


Table 13. The approximated groundwater pollutant concentration $\left(\mathrm{kg} / \mathrm{m}^{3}\right)$ of simulation 4.3 where $z=50 \mathrm{~m}$.

\begin{tabular}{lllllll}
\hline \multicolumn{7}{c}{$C(x, z, t)$} \\
\hline$t$ & $x=0$ & $x=20$ & $x=40$ & $x=60$ & $x=80$ & $x=90$ \\
\hline 5 & 0.0000 & 0.0000 & 0.0004 & 0.0025 & 0.0134 & 0.0270 \\
10 & 0.0012 & 0.0017 & 0.0045 & 0.0148 & 0.0453 & 0.0734 \\
15 & 0.0069 & 0.0085 & 0.0151 & 0.0348 & 0.0819 & 0.1203 \\
20 & 0.0194 & 0.0222 & 0.0329 & 0.0610 & 0.1209 & 0.1663 \\
\hline
\end{tabular}

Table 14. The approximated hydraulic head(m) of simulation 4.4 where $z=$ $50 \mathrm{~m}$.

\begin{tabular}{lllllll}
\hline \multicolumn{7}{c}{$H(x, z, t)$} \\
\hline$t$ & $x=0$ & $x=20$ & $x=40$ & $x=60$ & $x=80$ & $x=90$ \\
\hline 5 & 40.0000 & 37.2561 & 34.5325 & 31.8490 & 29.2244 & 27.9397 \\
10 & 40.0000 & 38.0587 & 36.1247 & 34.2049 & 32.3063 & 31.3670 \\
15 & 40.0000 & 38.4147 & 36.8333 & 35.2597 & 33.6977 & 32.9223 \\
20 & 40.0000 & 38.6272 & 37.2569 & 35.8918 & 34.5342 & 33.8590 \\
\hline
\end{tabular}

Table 15. The approximated groundwater flow velocity in $x$-direction(m/day) of simulation 4.4 where $z=50 \mathrm{~m}$.

\begin{tabular}{lllllll}
\hline \multicolumn{7}{c}{$u(x, z, t)$} \\
\hline$t$ & $x=0$ & $x=20$ & $x=40$ & $x=60$ & $x=80$ & $x=90$ \\
\hline 5 & 0.1371 & 0.1366 & 0.1348 & 0.1321 & 0.1285 & 0.1263 \\
10 & 0.0970 & 0.0968 & 0.0962 & 0.0952 & 0.0939 & 0.0931 \\
15 & 0.0792 & 0.0791 & 0.0788 & 0.0783 & 0.0775 & 0.0771 \\
20 & 0.0686 & 0.0686 & 0.0683 & 0.0680 & 0.0675 & 0.0672 \\
\hline
\end{tabular}

Table 16. The approximated groundwater flow velocity in $z$-direction(m/day) of simulation 4.4 where $z=50 \mathrm{~m}$.

\begin{tabular}{lllllll}
\hline \multicolumn{7}{c}{$w(x, z, t)$} \\
\hline$t$ & $x=0$ & $x=20$ & $x=40$ & $x=60$ & $x=80$ & $x=90$ \\
\hline 5 & 0 & 0 & 0 & 0 & 0 & 0 \\
10 & 0 & 0 & 0 & 0 & 0 & 0 \\
15 & 0 & 0 & 0 & 0 & 0 & 0 \\
20 & 0 & 0 & 0 & 0 & 0 & 0 \\
\hline
\end{tabular}

Table 17. The approximated groundwater pollutant concentration $\left(\mathrm{kg} / \mathrm{m}^{3}\right)$ of simulation 4.4 where $z=50 \mathrm{~m}$.

\begin{tabular}{lllllll}
\hline \multicolumn{7}{c}{$C(x, z, t)$} \\
\hline$t$ & $x=0$ & $x=20$ & $x=40$ & $x=60$ & $x=80$ & $x=90$ \\
\hline 5 & 0.0000 & 0.0001 & 0.0007 & 0.0050 & 0.0268 & 0.0540 \\
10 & 0.0023 & 0.0034 & 0.0090 & 0.0297 & 0.0906 & 0.1468 \\
15 & 0.0138 & 0.0170 & 0.0303 & 0.0697 & 0.1639 & 0.2406 \\
20 & 0.0389 & 0.0444 & 0.0658 & 0.1220 & 0.2418 & 0.3327 \\
\hline
\end{tabular}

Table 18. The approximated hydraulic head(m) of simulation 4.5 where $z=$ $50 \mathrm{~m}$.

\begin{tabular}{lllllll}
\hline \multicolumn{7}{c}{$H(x, z, t)$} \\
\hline$t$ & $x=0$ & $x=20$ & $x=40$ & $x=60$ & $x=80$ & $x=90$ \\
\hline 5 & 36.4000 & 33.4092 & 30.4953 & 27.7080 & 25.0706 & 23.8111 \\
10 & 36.4000 & 33.9669 & 31.6015 & 29.3447 & 27.2115 & 26.1917 \\
15 & 36.4000 & 34.1979 & 32.0615 & 30.0295 & 28.1148 & 27.2014 \\
20 & 36.4000 & 34.3326 & 32.3299 & 30.4300 & 28.6448 & 27.7948 \\
\hline
\end{tabular}

Table 19. The approximated groundwater flow velocity in $x$-direction(m/day) of simulation 4.5 where $z=50 \mathrm{~m}$.

\begin{tabular}{lllllll}
\hline \multicolumn{7}{c}{$u(x, z, t)$} \\
\hline$t$ & $x=0$ & $x=20$ & $x=40$ & $x=60$ & $x=80$ & $x=90$ \\
\hline 5 & 0.1490 & 0.1470 & 0.1411 & 0.1338 & 0.1260 & 0.1220 \\
10 & 0.1212 & 0.1194 & 0.1143 & 0.1082 & 0.1020 & 0.0989 \\
15 & 0.1096 & 0.1080 & 0.1030 & 0.0972 & 0.0913 & 0.0885 \\
20 & 0.1029 & 0.1013 & 0.0964 & 0.0907 & 0.0850 & 0.0823 \\
\hline
\end{tabular}

Table 20. The approximated groundwater flow velocity in $z$-direction(m/day) of simulation 4.5 where $z=50 \mathrm{~m}$.

\begin{tabular}{lllllll}
\hline \multicolumn{7}{c}{$w(x, z, t)$} \\
\hline$t$ & $x=0$ & $x=20$ & $x=40$ & $x=60$ & $x=80$ & $x=90$ \\
\hline 5 & -0.0600 & -0.0472 & -0.0366 & -0.0287 & -0.0228 & -0.0205 \\
10 & -0.0600 & -0.0473 & -0.0369 & -0.0291 & -0.0233 & -0.0211 \\
15 & -0.0600 & -0.0473 & -0.0369 & -0.0291 & -0.0234 & -0.0212 \\
20 & -0.0600 & -0.0473 & -0.0369 & -0.0291 & -0.0234 & -0.0212 \\
\hline
\end{tabular}

Table 21. The approximated groundwater pollutant concentration $\left(\mathrm{kg} / \mathrm{m}^{3}\right)$ of simulation 4.5 where $z=50 \mathrm{~m}$.

\begin{tabular}{lllllll}
\hline \multicolumn{7}{c}{$C(x, z, t)$} \\
\hline$t$ & $x=0$ & $x=20$ & $x=40$ & $x=60$ & $x=80$ & $x=90$ \\
\hline 5 & 0.0000 & 0.0001 & 0.0008 & 0.0064 & 0.0360 & 0.0733 \\
10 & 0.0008 & 0.0014 & 0.0053 & 0.0237 & 0.0885 & 0.1537 \\
15 & 0.0038 & 0.0050 & 0.0124 & 0.0419 & 0.1311 & 0.2132 \\
20 & 0.0093 & 0.0112 & 0.0217 & 0.0600 & 0.1669 & 0.2606 \\
\hline
\end{tabular}

\section{Discussion}

The hydraulic head can drive the groundwater flow from the higher hydraulic head level zone to the lower zone, as shown in Tables 2-4, 6-8, 10-12, and 14-16. The direction of groundwater is illustrated by their velocity field, as shown in Fig 46, 9-11, 14-16, and 19-20. In Simulation 4.1, a case of low leachate pollutant release rate from a landfill with a low-level hydraulic head is considered. If the level of the hydraulic head is increased fourfold, the overall groundwater quality becomes close to the last case, as shown in Simulation 4.2. On the other hand, if the level of leachate pollutant release rate is increased, the overall groundwater quality becomes as poor as the pollutant concentration at the considered landfill, as shown in Simulation 4.3. If the leachate releasing rate is poor or there is a high pollutant concentration, the overall groundwater quality becomes poor as well, as shown in Simulation 4.4. In Simulation 4.5 , a case of practical leachate pollutant releasing rate is also tested by using numerical data interpolation $f_{L}(x)$.

\section{Conclusion}

Three two-dimensional models of long-term contaminated groundwater pollutant measurement around a landfill are introduced. The first model is the two-dimensional transient groundwater flow model, which provides the hydraulic head. The second model is the groundwater flow velocity model, which provides the groundwater flow velocity in the $\mathrm{x}$ - and $\mathrm{z}-$ directions. The third model is the two-dimensional horizontal averaged contaminated groundwater dispersion model, which provides the groundwater pollutant concentration. A method to set up the initial condition and boundary conditions of the 
proposed transient groundwater flow model is proposed. The computed hydraulic head is transformed to be the groundwater flow velocity by using the second model. The results from the second model will be inputted into the third model as field data. The groundwater pollutant concentration is obtained by the third model. The hydraulic head of the first model is approximated by an explicit finite difference method. An explicit finite difference technique is used to obtain the groundwater flow velocity of the second model. A forward time centered space finite difference technique is used to approximate the groundwater pollutant concentration. Long term groundwater quality around the landfill for 5, 10, 15, and 20 years are simulated. The groundwater quality is affected by the contaminated leachate pollutant release by the landfill. The proposed simulations show that the different levels of hydraulic head have a small effect on the overall groundwater quality level. Our proposed simulations found that the main groundwater quality factor is the leachate pollutant concentration around the landfill. Furthermore, a three-dimensional mathematical model for contaminated groundwater pollutant measurement should be introduced for a precise simulation.

\section{Acknowledgment}

This paper is supported by the Centre of Excellence in Mathematics, the Commission on Higher Education, Thailand. The authors greatly appreciate valuable comments received from the anonymous reviewers.

\section{REFERENCES}

[1] K. Halil and M. Tammer Ayvaz, Transient groundwater modeling using spreadsheets. Advances in Engineering Software, 36 (2005) 374-384.

[2] N. Pochai and N. Pongnu, Numerical solution of groundwater measurement using alternating direction methods. Journal of Interdisciplinary Mathematics, vol 20 (2017), No. 2, 513-541.

[3] N. Pochai, Numerical Treatment of a Modified MacCormack Scheme in a Nondimensional Form of the Water Quality Models in a Nonuniform Flow Stream. Journal of Applied Mathematics, Volume 2014, Article ID 274263, 8 pages .

[4] N. Pochai, S. Tangmanee, L. J. Crane, and J. J. Miller, A mathematical model of water pollution control using the finite element method. Proceedings in Applied Mathematics and Mechanics, vol 6 (2006), no. 1, 755-756.

[5] N. Pochai, S. Tangmanee, L. J. Crane, and J. J. Miller, A water quality computation in the uniform channel. Journal of Interdisciplinary Mathematics, vol 11 (2008), no. 6, 803-814.

[6] N. Pochai and C. Sornsri, A Non-dimensional Form of Hydrodynamic Model with Variable Coefficients in a
Uniform Reservoir Using Lax-Wendroff Method. Procedia Engineering, 8 (2011), 89-93.

[7] G. Amin, Explicit and implicit forms of differential quadrature method for advection-diffusion equation with variable coefficients in semi-infinite domain. Journal of Hydrology, 541 (2016) 935-940.

[8] N. Pochai and R. Deepana, A Numerical Computation of Water Quality Measurement in a Uniform Channel Using a Finite Difference Method. Procedia Engineering, 8 (2011) 85-88.

[9] Cryer CW, On the approximate solution of free boundary problems using finite difference. Journal of the Association for Computing Machinary, vol 17 (1970), 397-411.

[10] Bardet JP and Tobita T, A practical method for solving free-surface seepage problems. Computers and Geotechnics, 29 (2002), 451-475.

[11] Ayvaz MT, Tuncan M, Karahan H and Tuncan A, An extended presure application for transient seepage problems with a free surface. Journal of Porous Media, 8 (2005), 613-625.

[12] Desai CS and Li GC, A residual flow procedure and application for free surface flow in porous media. Advances in Water Resources, 6 (1983), 27-35

[13] Kikuchi N, An analysis of the variational inequalities of seepage flow by finite element methods. Quarterly of Applied Mathematics, 35 (1977), 149-163.

[14] Tatfur G, Swiatek D, Wita A and Singh VP, Case study: Finite element method and artificial neural network models for flow through Jeziorsko earthfill dam in Poland. Journal of Hydraulic Engineering, 191 (2005), 431-440. 


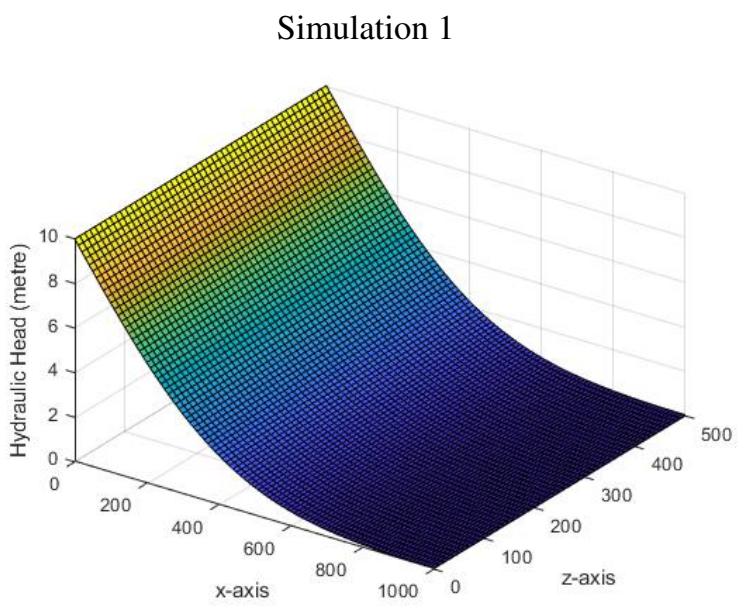

Figure 4. The surface plot of hydraulic head $H_{i, j}^{n}$ for all $(x, z, t) \in$ $[0,1000] \times[0,500] \times[0,3600]$.

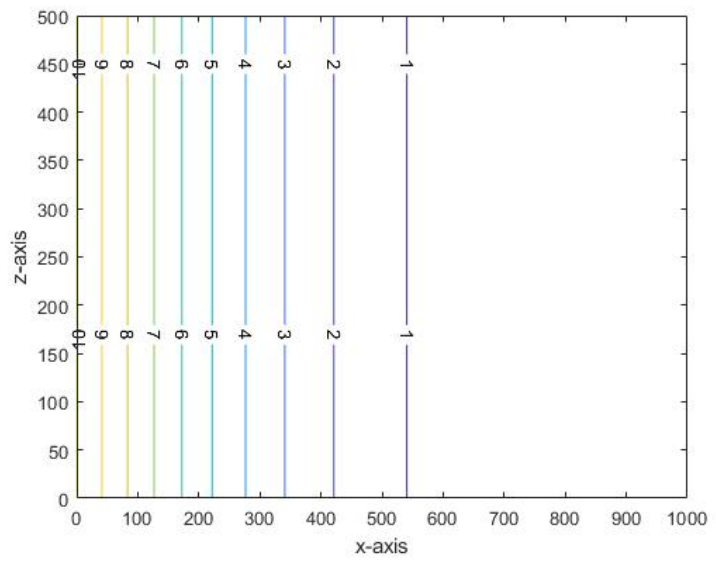

Figure 5. The contour plot of hydraulic head $H_{i, j}^{n}$ for all $(x, z, t) \in$ $[0,1000] \times[0,500] \times[0,3600]$.

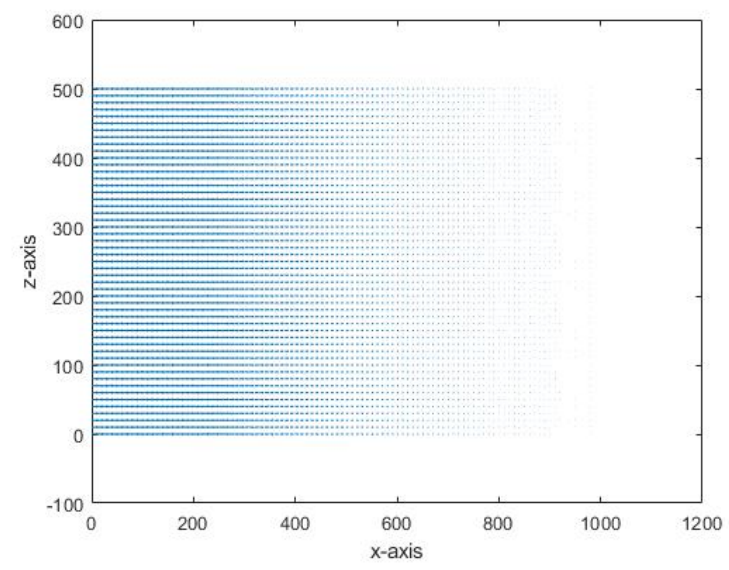

Figure 6. The velocity field of hydraulic head

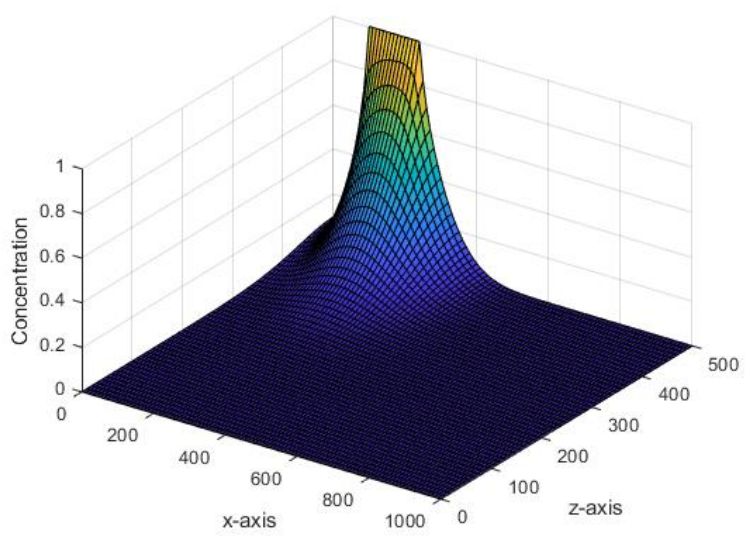

Figure 7. The surface plot of contaminated $c_{i, j}^{n}$ for all $(x, z, t) \in[0,1000] \times$ $[0,500] \times[0,3600]$.

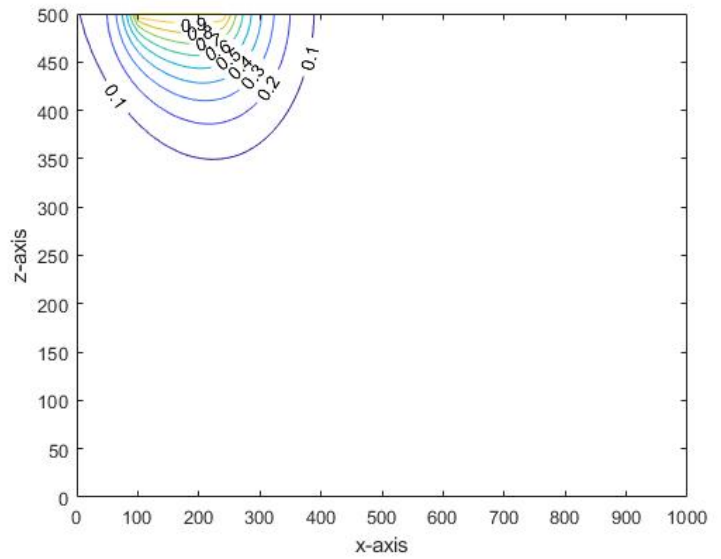

Figure 8. The contour plot of contaminated $c_{i, j}^{n}$ for all $(x, z, t) \in[0,1000] \times$ $[0,500] \times[0,3600]$.

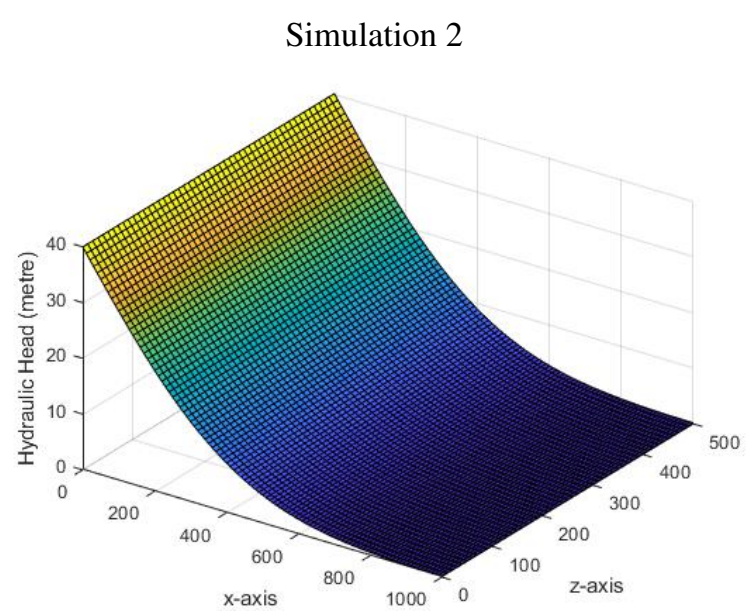

Figure 9. The surface and contour plot of hydraulic head $H_{i, j}^{n}$ for all $(x, z, t) \in[0,1000] \times[0,500] \times[0,3600]$. 


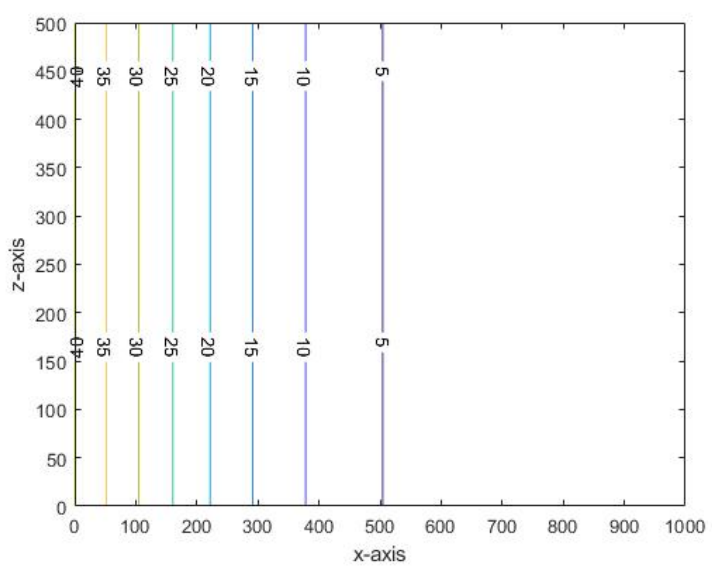

Figure 10. The surface and contour plot of hydraulic head $H_{i, j}^{n}$ for all $(x, z, t) \in[0,1000] \times[0,500] \times[0,3600]$.

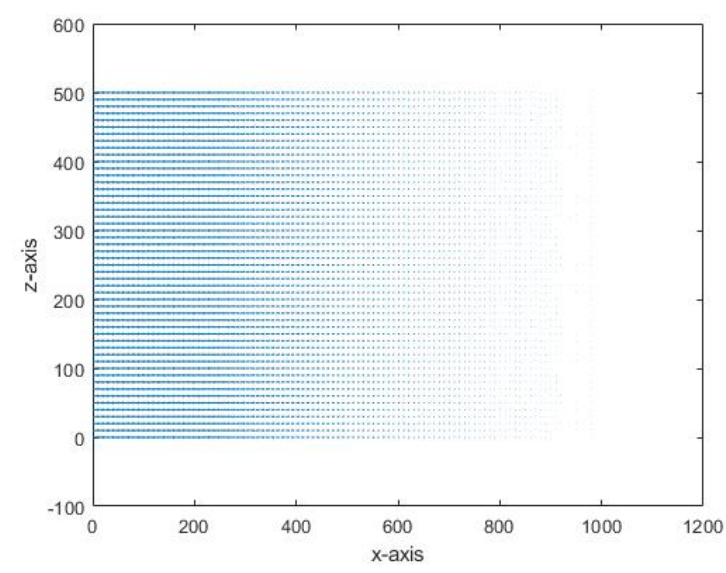

Figure 11. The velocity field of hydraulic head

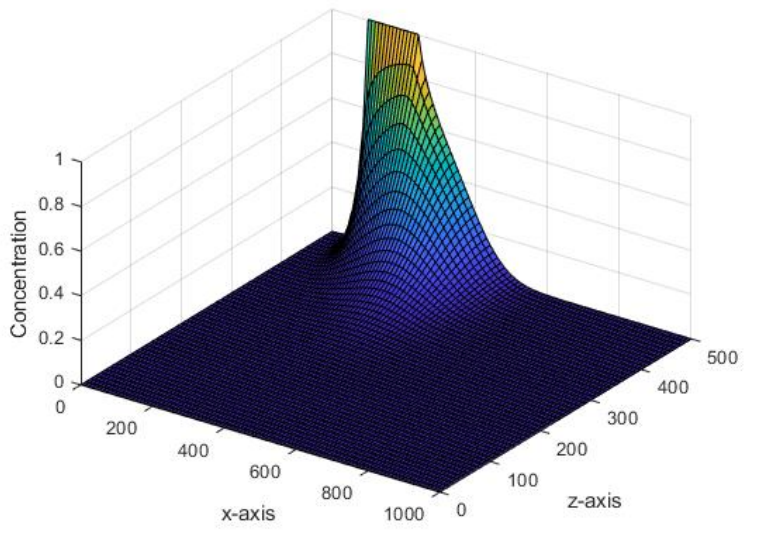

Figure 12. The surface of contaminated $c_{i, j}^{n}$ for all $(x, z, t) \in[0,1000] \times$ $[0,500] \times[0,3600]$.

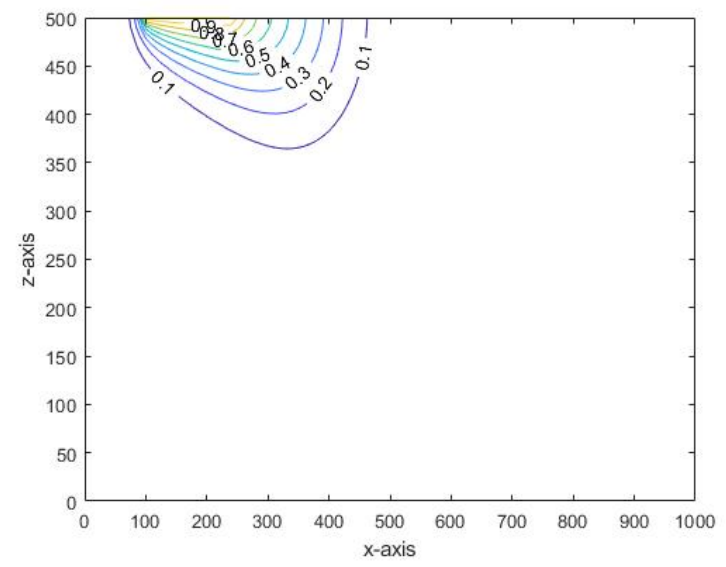

Figure 13. The contour plot of contaminated $c_{i, j}^{n}$ for all $(x, z, t) \in$ $[0,1000] \times[0,500] \times[0,3600]$.

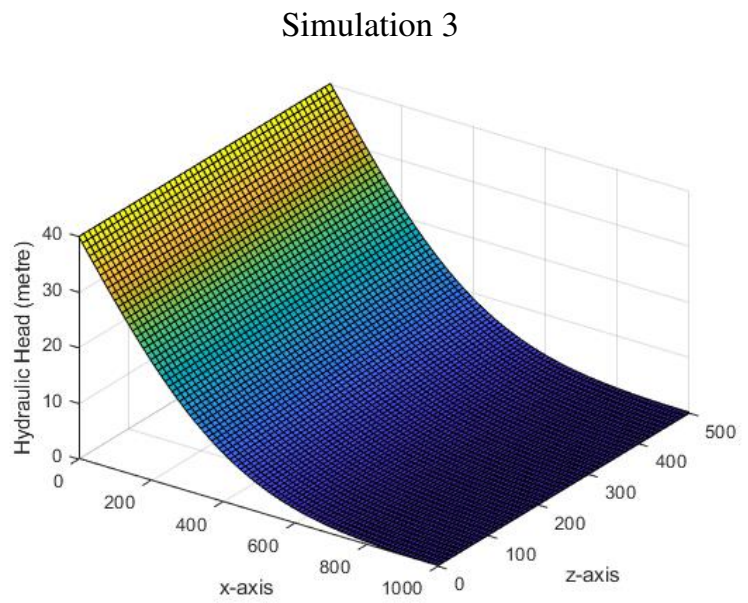

Figure 14. The surface plot of hydraulic head $H_{i, j}^{n}$ for all $(x, z, t) \in$ $[0,1000] \times[0,500] \times[0,3600]$.

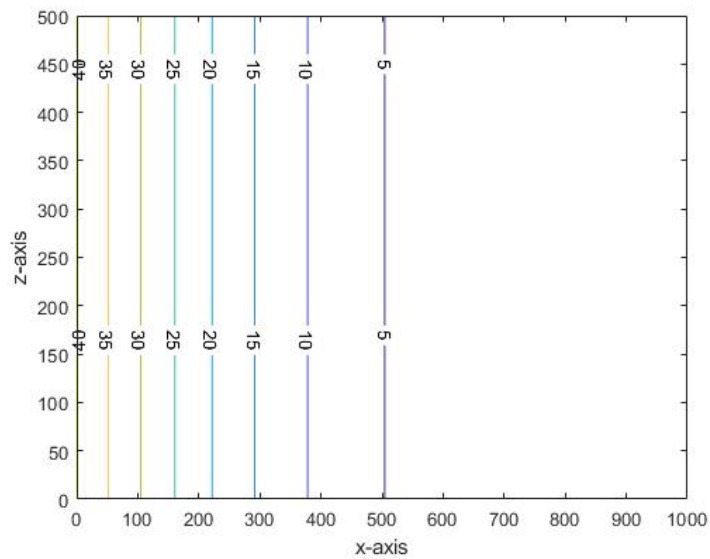

Figure 15. The contour plot of hydraulic head $H_{i, j}^{n}$ for all $(x, z, t) \in$ $[0,1000] \times[0,500] \times[0,3600]$. 


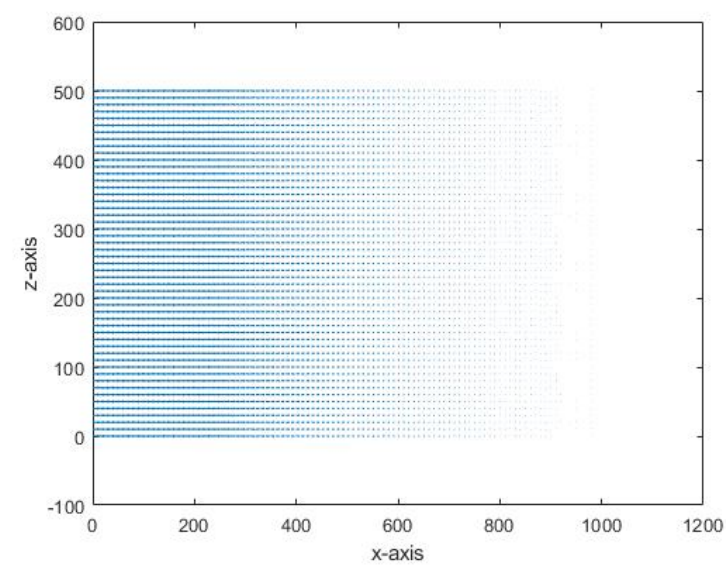

Figure 16. The velocity field of hydraulic head

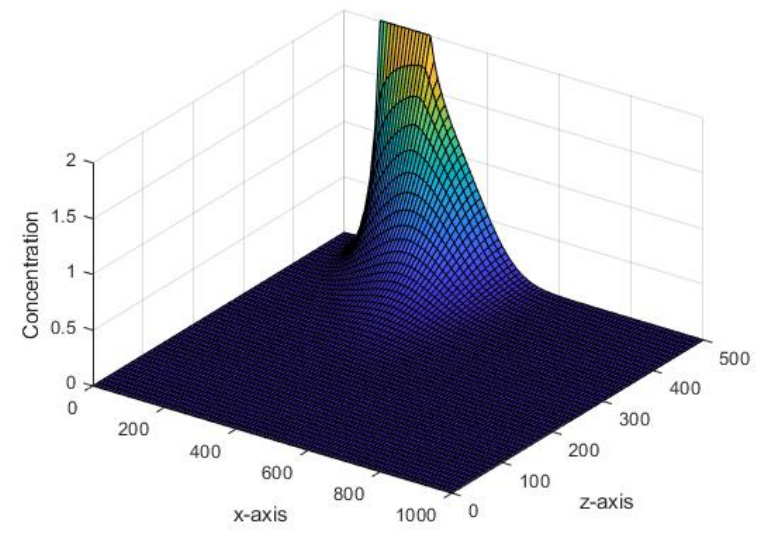

Figure 17. The surface and contour plot of contaminated $c_{i, j}^{n}$ for all $(x, z, t) \in$ $[0,1000] \times[0,500] \times[0,3600]$.

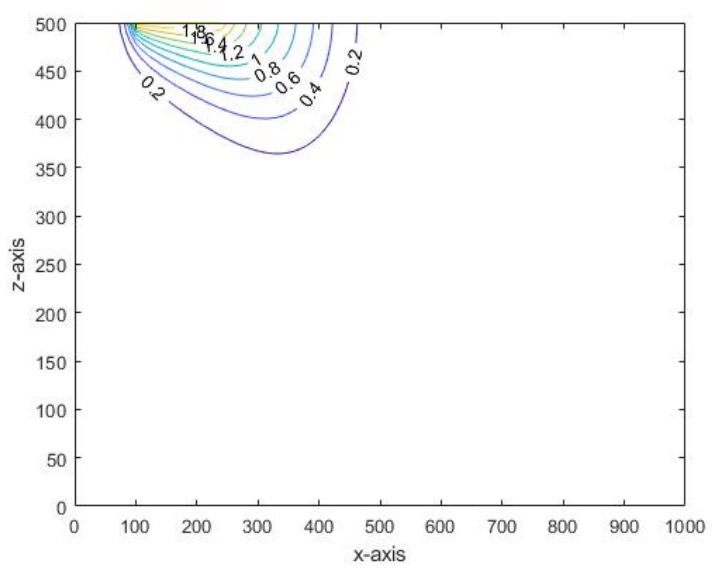

Figure 18. The surface and contour plot of contaminated $c_{i, j}^{n}$ for all $(x, z, t) \in$ $[0,1000] \times[0,500] \times[0,3600]$.

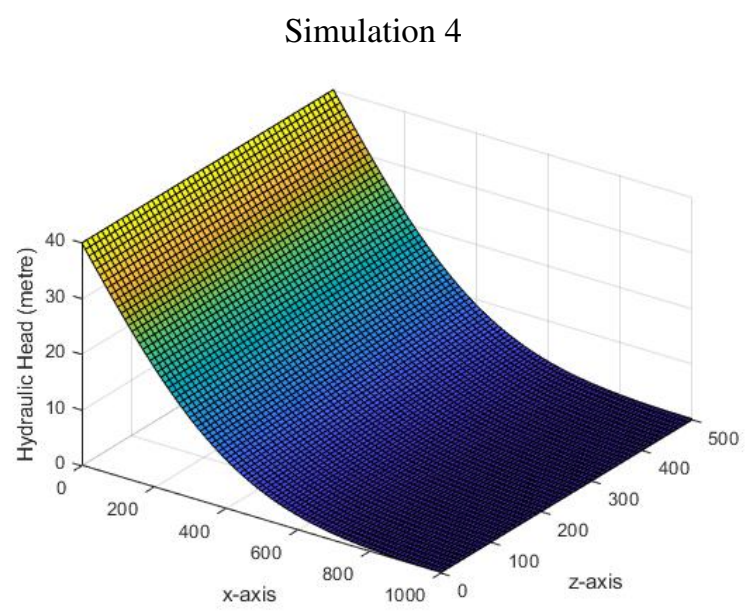

Figure 19. The surface plot of hydraulic head $H_{i, j}^{n}$ for all $(x, z, t) \in$ $[0,1000] \times[0,500] \times[0,3600]$.

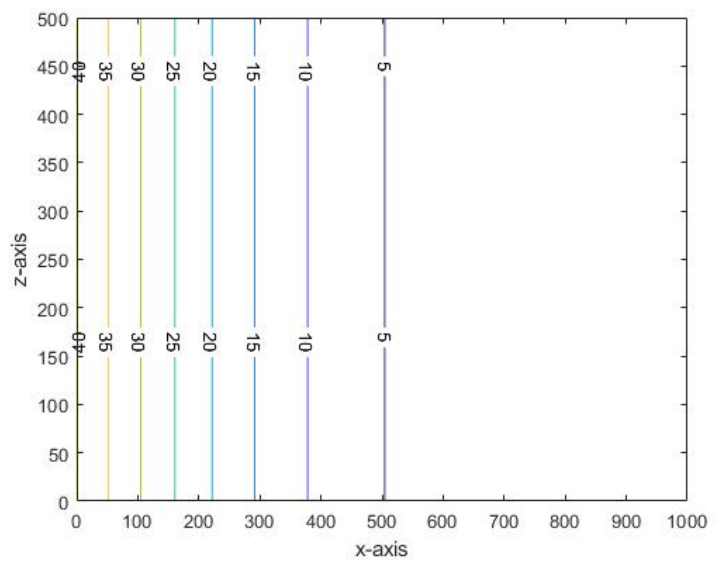

Figure 20. The contour plot of hydraulic head $H_{i, j}^{n}$ for all $(x, z, t) \in$ $[0,1000] \times[0,500] \times[0,3600]$.

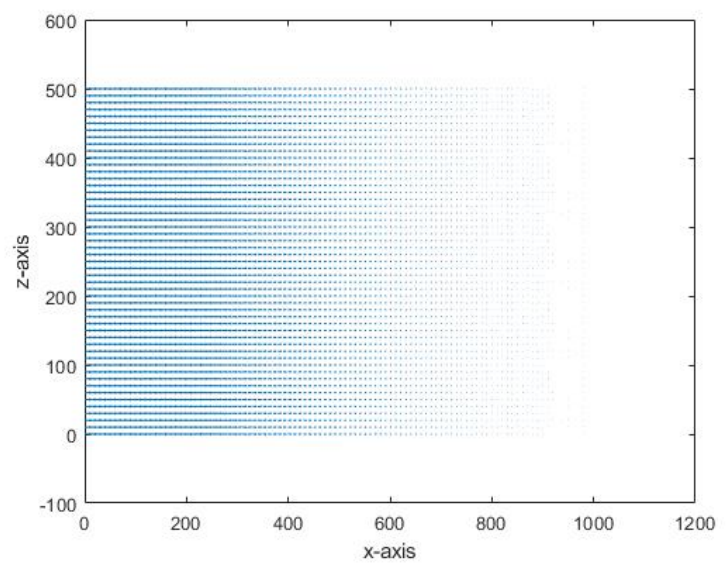

Figure 21. The velocity field of hydraulic head 


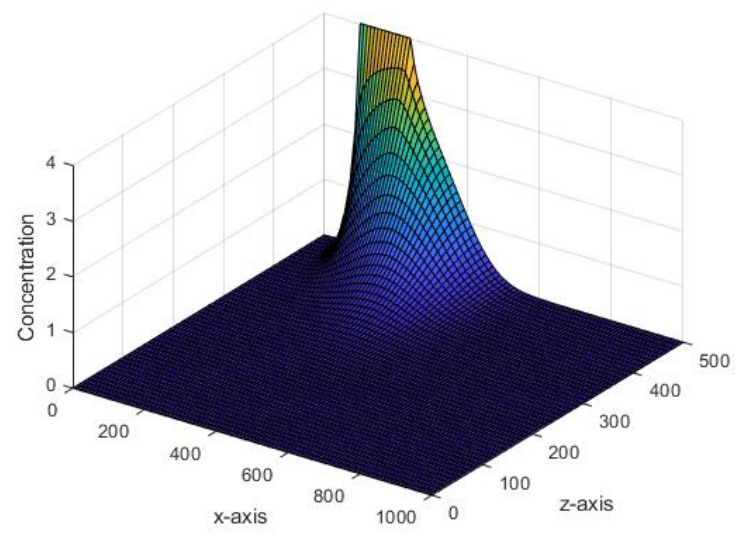

Figure 22. The surface plot of contaminated $c_{i, j}^{n}$ for all $(x, z, t) \in[0,1000] \times$ $[0,500] \times[0,3600]$.

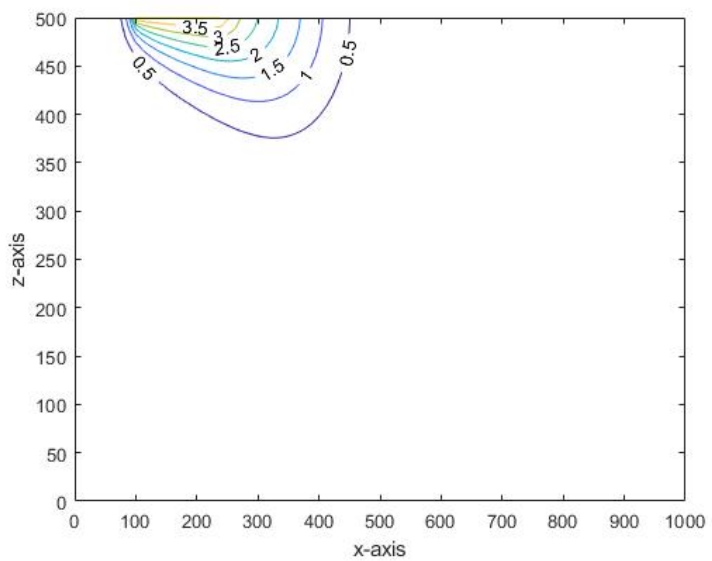

Figure 23. The contour plot of contaminated $c_{i, j}^{n}$ for all $(x, z, t) \in$ $[0,1000] \times[0,500] \times[0,3600]$.

Simulation 5

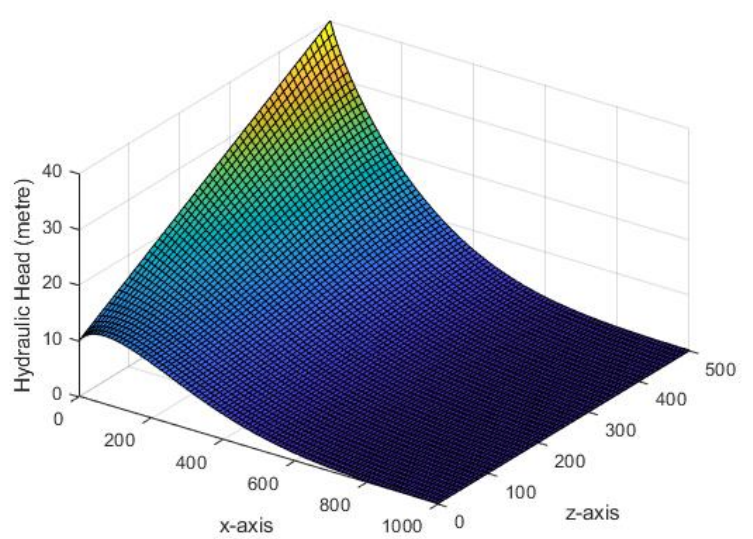

Figure 24. The surface plot of hydraulic head $H_{i, j}^{n}$ for all $(x, z, t) \in$ $[0,1000] \times[0,500] \times[0,3600]$.

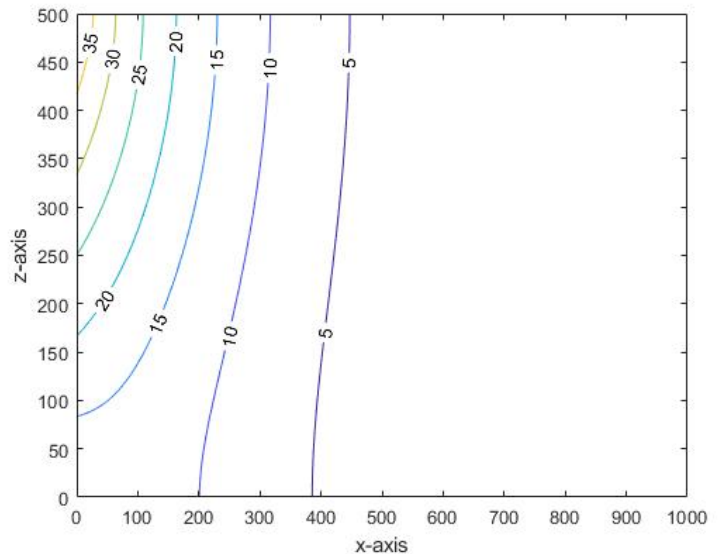

Figure 25. The contour plot of hydraulic head $H_{i, j}^{n}$ for all $(x, z, t) \in$ $[0,1000] \times[0,500] \times[0,3600]$.

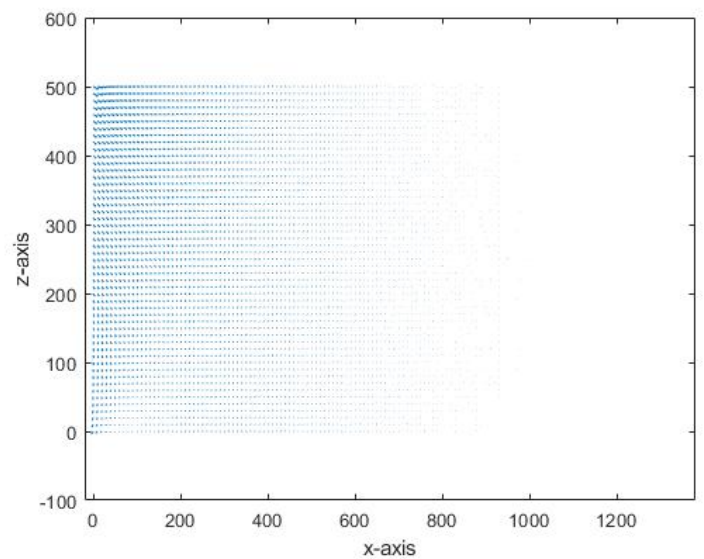

Figure 26. The velocity field of hydraulic head

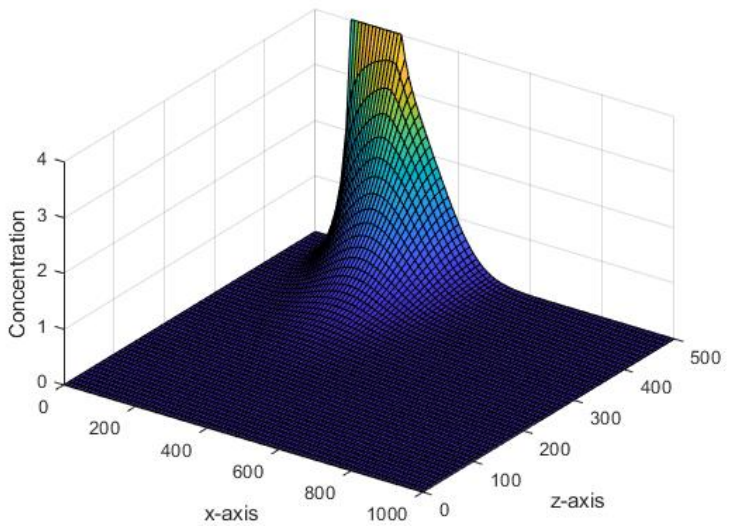

Figure 27. The surface plot of contaminated $c_{i, j}^{n}$ for all $(x, z, t) \in[0,1000] \times$ $[0,500] \times[0,3600]$. 


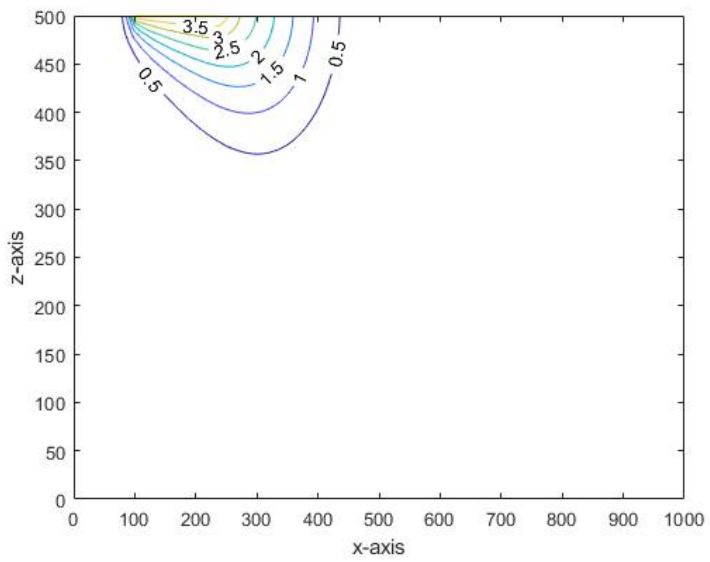

Figure 28. The contour plot of contaminated $c_{i, j}^{n}$ for all $(x, z, t) \in$ $[0,1000] \times[0,500] \times[0,3600]$. 